\title{
The utility of Ki-67 and BrdU as proliferative markers of adult neurogenesis
}

\author{
N. Kee ${ }^{1}$, S. Sivalingam ${ }^{1}$, R. Boonstra, J.M. Wojtowicz* \\ Department of Physiology, Medical Sciences Building, University of Toronto, Toronto, Ont., Canada M5S 1A8
}

Received 20 August 2001; received in revised form 4 January 2002; accepted 4 January 2002

\begin{abstract}
Adult animals continue to produce new neurons in the dentate gyrus of hippocampus. Until now, the principal method of studying neurogenesis has been to inject either tritiated thymidine or 5'-Bromo-2-deoxyuridine (BrdU) intraperitoneally followed by autoradiographic or immunohistochemical detection methods respectively. However, such exogenous markers may produce toxic effects. Our objective was to determine whether Ki-67, a nuclear protein expressed in all phases of the cell cycle except the resting phase, can be used as an alternative, endogenous marker. Using immunohistochemistry, we examined Ki-67 and BrdU expression pattern in rats. Ki-67 was expressed within the proliferative zone of the dentate gyrus and its expression pattern mimicked that of BrdU when examined soon after exogenous BrdU administration. Quantitative comparison of BrdU and Ki-67-positive cells showed $50 \%$ higher numbers of the latter when examined $24 \mathrm{~h}$ after the BrdU injection. This was expected, since BrdU can be incorporated into DNA only during the S-phase of the mitotic process, whereas Ki-67 is expressed for its whole duration. Experimental increases (by ischemia) or reductions (by radiation) in the number of mitotic cells produced parallel changes in BrdU and Ki-67 signals. Thus, Ki-67 is an effective mitotic marker and has most of the benefits of BrdU and none of the costs. This study provides evidence for Ki-67 to be used as a marker of proliferation in the initial phase of adult neurogenesis. (C) 2002 Elsevier Science B.V. All rights reserved.
\end{abstract}

Keywords: Neurogenesis; Cell proliferation; Hippocampus; Dentate gyrus; Mitotic indicator; 5-Bromo-2-deoxyuridine; Ki-67; Immunohistochemistry

\section{Introduction}

5-Bromo-2-deoxyuridine (BrdU) has been a principal marker for mitotic cells in studies of adult neurogenesis (Gratzner, 1982). The method consists of a pulse injection of BrdU into the intraperitoneal cavity followed by a variable survival time allowing for tracking the fate of divided cells and their progeny. At the end of the experiment, the animal is sacrificed and the tissues fixed with a standard paraformaldehyde-based fixative. BrdU is detected in the tissue using specific primary antibodies. The primary antibodies are then labeled with a secondary antibody tagged with a fluorescent compound or with a substrate for diaminobenzidine (DAB)

\footnotetext{
* Corresponding author. Tel.: +1-416-978-2899; fax: +1-416-9784940.

E-mail address: martin.wojtowicz@utoronto.ca (J.M. Wojtowicz).

${ }^{1}$ Equal contribution.
}

(Seki and Arai, 1993; Scott et al., 2000). The substitution of an endogenous DNA base, Thymidine, with the BrdU analogue ensures specific labeling of only the dividing cells. This specificity of BrdU combined with the high sensitivity of fluorescence microscopy, including confocal microscopy has led to the great popularity of the method. It is believed that the application of this BrdU method contributed to the current acceptance of neurogenesis as a natural process in the brain of adult mammals (Gross, 2000). One useful feature of BrdU is its long-term retention in divided cells and its passage to their daughter cells. This feature can be used to trace the cell lineage and cell survival. A spectacular example of such use was a study by Eriksson and colleagues who injected patients with BrdU and then examined brain tissue postmortem up to 2 years later. BrdU was detected in the brains of these patients and double labeling confirmed that the surviving cells were neurons (Eriksson et al., 1998). 
However, the undeniable usefulness of the BrdU method goes hand in hand with its limitations and drawbacks. The possibility of BrdU producing mutated cells and the consequent severe abnormalities of the developing tissues has been reported (Kolb et al., 1999). These side effects aside, the use of BrdU in whole-animal experiments is difficult due to uncertainty of diffusion of this substance among the various tissues of the body following intraperitoneal injection. For example, the blood brain barrier may prevent the BrdU from freely penetrating the brain tissue, especially in old animals (Cameron and McKay, 2001). In certain species of rodents, the effective incorporation of exogenous tritiated thymidine ( $\left.{ }^{3} \mathrm{HThy}\right)$ in DNA synthesis in some tissues was lacking (Adelstein et al., 1964). Since both BrdU and ${ }^{3}$ HThy may use the same transport mechanisms (Cameron and McKay, 2001), a comparative study of mitosis in different tissues and/or species, using BrdU as a mitotic marker, could be difficult. Stress is known to inhibit neurogenesis (Cameron and Gould, 1994; Gould et al., 1997) and therefore the handling and the BrdU injection procedure is likely to have an unintended effect on the rate of neurogenesis.

Given these drawbacks, an alternative method is highly desirable. Here we report on the use of Ki-67, a nuclear protein, expressed in dividing cells for the entire duration of their mitotic process (Scholzen and Gerdes, 2000). Like BrdU, Ki-67 can be detected with immunohistochemistry. Unlike BrdU, Ki-67 is an endogenous marker that does not have any adverse effects on living cells. Although the function of Ki-67 is not known, it is a reliable marker of mitosis because it is expressed, albeit at different levels, during mitosis and its half-life is very short. Moreover, studies reported thus far show that Ki-67 is expressed during mitosis in all mammalian species from rodents to humans (Scholzen and Gerdes, 2000; Endl and Gerdes, 2000). We focused our attention on the use of Ki-67 in the brain tissue, especially in the hippocampal dentate gyrus, because of the current interest in the possible consequences of nerve cell proliferation on cognition and behaviour (Boonstra et al., 2001a). One example of such use of Ki-67 is already available in the study by Tanapat et al. (1999). In that study a difference between the rate of adult neurogenesis, as indicated by BrdU labeling, between male and female rats was found. Yet the numbers of Ki-67 labeled cells were the same in males and females. They concluded that perhaps the slower cell cycle, that would not be detectable by $\mathrm{Ki}-67$, was responsible for the discrepancy although other interpretations are also possible. In the present study we show a comparison of BrdU and Ki-67 labeling in various experiments and combine their use with the neuronal markers neuronal nuclear protein (NeuN) (Mullen et al., 1992), and collapsin response mediator protein-4 (CRMP-4) (Quinn et al., 1999). Our results will clarify the pros and cons of $\mathrm{Ki}-67$ as a mitotic marker and make its use routine and easier to interpret in future studies of adult neurogenesis.

\section{Methods}

\subsection{BrdU administration}

The thymidine analogue BrdU (Sigma, St. Louis, MO) was administered intraperitoneally in pulse injections of the stock solution. BrdU stock was prepared in phosphate buffered saline (PBS), $(\mathrm{pH} 7.2,0.1 \mathrm{M})$ with $0.1 \mathrm{~N} \mathrm{NaOH}$ at $20 \mathrm{mg} / \mathrm{ml}$.

\subsection{Animal groups}

In experiment 1 (effects of intraperitoneal injections) the subjects were young adult (35-40 days) male Wistar rats (Charles River). A pulse injection of $300 \mathrm{mg} / \mathrm{kg}$ was given to one group of animals $(n=3)$. To control for possible toxic or stress-related effects due to the injection of BrdU, we compared the BrdU-injected group with a second group $(n=3)$ injected with the equivalent amount of saline, and with a third control $(n=3)$ group that was not injected. Animals in all groups were sacrificed $24 \mathrm{~h}$ after the injections.

In experiment 2 (effects of gamma irradiation) young adult (35-60 days) male Wistar rats were used. The procedure and the handling of animals were significantly different from those described by us previously (Snyder et al., 2001) so we give more details. In each case the animal was anesthetized with Somnotol $(60 \mathrm{mg} / \mathrm{kg})$. The head portion of the experimental rats $(n=2)$ was exposed to focused beam gamma irradiation (Theratron, ${ }^{60} \mathrm{Co}$ source) for a dose of $10 \mathrm{~Gy}$, while the sham rats $(n=4)$ were not exposed to radiation. Four sham animals were sacrificed 3 days, 1, 2 and 3 weeks after the procedure respectively. Two irradiated animals were sacrificed 3 weeks after the procedure. Each animal was injected with a single dose of $300 \mathrm{mg} / \mathrm{kg} \mathrm{BrdU}$ and perfused $2 \mathrm{~h}$ afterwards to assess cell proliferation in the dentate gyrus.

In experiment 3 (effects of ischemia) male adult ( $>3$ months old) Sprague-Dawley rats $(n=3$ for ischemic and $n=3$ for sham controls) were used. In this group we gave 3 injections of $\mathrm{BrdU}(100 \mathrm{mg} / \mathrm{kg}$ total) in $12 \mathrm{~h}$ to each rat. This dosage was used for consistency with our previous studies of neurogenesis and ischemia (Snyder et al., 2001; Kee et al., 2001). Other procedures for the ischemia experiment were exactly the same as described before (Kee et al., 2001). 


\subsection{Tissue preparation for immunohistochemistry}

Animals were anaesthetized with Somnotol $(60 \mathrm{mg} /$ kg; MTC pharmaceuticals, Ontario). They were perfused transcardially with ice-cold PBS, followed by icecold $4 \%$ paraformaldehyde in $0.1 \mathrm{M}$ phosphate buffer (PB, pH 7.4), after which the brains were extracted. The hippocampus was removed and postfixed overnight in the paraformaldehyde fixative. It was then mounted and sectioned transversally on a vibratome at $30 \mu \mathrm{m}$ and the slices were stored in PBS containing 0.1\% sodium azide at $4{ }^{\circ} \mathrm{C}$ until use.

\subsection{BrdU immunohistochemistry}

Tissue to be labeled was washed with PBS to remove any sodium azide prior to immunolabeling. Sections were incubated in wells (48 well Nunc Multidish) containing the desired antibody solutions. For immunohistochemical detection of BrdU-incorporating nuclei, DNA was first denatured to expose the antigen by incubating the tissue sections in $1 \mathrm{~N} \mathrm{HCl}$ for $45 \mathrm{~min}$ at $45{ }^{\circ} \mathrm{C}$ as described by Kee et al. (2001). The sections were rinsed three times for $5 \mathrm{~min}$ each in PBS, then incubated with primary antibody to BrdU (rat monoclonal; Accurate Chemical, 1:200 in 0.3\% Triton-X solution) for $48 \mathrm{~h}$ at $4{ }^{\circ} \mathrm{C}$. Next, the labeled sections were washed with PBS (3 times at $5 \mathrm{~min}$ each) and secondary incubation was carried out in the dark for $2 \mathrm{~h}$ at room temperature. For the secondary incubation, fluorochrome-conjugated secondary antibody (Alexa 488 goat anti-rat; Chemicon) was diluted at 1:200 in $0.3 \%$ Triton-X solution. After $2 \mathrm{~h}$ the tissue was washed in PBS, rinsed with double-distilled water and mounted onto slides using an anti-fade mounting medium (Permafluor, Molec. Probes). The slides were allowed to air dry in the dark at room temperature and then stored at $4{ }^{\circ} \mathrm{C}$ until used for analysis.

\subsection{Ki-67 immunohistochemistry}

Sections were washed with PBS to remove any sodium azide and then incubated with Ki-67 antibody. The Ki67 antibody (NCL-Ki-67-MM1; NovoCastra Labs Ltd.) was diluted at a ratio of 1:200 in 0.3\% Triton-X in PBS solution and sections to be labeled were allowed to incubate for $48 \mathrm{~h}$ at $4{ }^{\circ} \mathrm{C}$ with gentle shaking. The sections were then washed three times at 5 min each in PBS, followed by a $2 \mathrm{~h}$ incubation with fluorescentconjugated secondary antibody (Alexa 568/488 goat anti-mouse, 1:200 in 0.3\% Triton-X solution; Chemicon) at room temperature. Sections were then rinsed and mounted as described above.

\section{6. $\mathrm{Ki}-67+\mathrm{BrdU}$ co-labeling}

Ki-67 labeling was performed as described above. Once the sections were washed after the secondary antibody incubation and observed under a wet mount, they were post-fixed in $8 \%$ paraformaldehyde in $0.1 \mathrm{M}$ phosphate buffer (PB, $\mathrm{pH}$ 7.4) for $15 \mathrm{~min}$. This was necessary to protect the $\mathrm{Ki}-67$ signals from the $\mathrm{HCl}$ treatment (Palmer et al., 2000). Sections were then washed three times at $5 \mathrm{~min}$ each and processed for BrdU labeling as described above.

\subsection{Ki-67+CRMP-4 co-labeling}

Ki-67 labeling was performed as described above. For CRMP-4 co-labeling, the Ki-67 labeled sections were washed with PBS, then incubated in primary antibody to CRMP-4 (1:500 in 0.3\% Triton-X solution, Antirabbit; Chemicon) for $72 \mathrm{~h}$ at $4{ }^{\circ} \mathrm{C}$ with gentle shaking. The sections were washed three times at $5 \mathrm{~min}$ each in PBS. The resulting sections were incubated for $2 \mathrm{~h}$ in the dark at room temperature in fluorescent-conjugated secondary antibody (Alexa 488, goat anti-rabbit; Chemicon). Sections were washed again thoroughly in PBS and finally mounted onto slides with Permafluor.

\subsection{Ki-67+NeuN co-labeling}

Ki-67 labeling was performed as described above, however, the secondary incubation with the flurochrome-conjugated antibody (Alexa 488 goat antimouse) was left overnight. After the secondary incubation was completed, tissue sections were washed three times to ensure that only bound Alexa 488 antibodies remain. This was necessary to avoid nonspecific binding. Next, an Alexa 568 anti-mouse antibody (1:200 in 0.3\% Triton-X) was added and incubated for $2 \mathrm{~h}$. Slices were washed with PBS and incubated for $24 \mathrm{~h}$ at $4{ }^{\circ} \mathrm{C}$ with gentle shaking with anti-NeuN antibody (MsX NeuN; Chemicon), diluted at 1:1000 in 0.3\% Triton-X in PBS. The sections were then washed in PBS and subsequently incubated with Alexa 568 goat anti-mouse (1:200 in $0.3 \%$ Triton-X solution) for $2 \mathrm{~h}$ in the dark. Sections were washed thoroughly and mounted.

\subsection{Quantification of labeled cells}

A stereological counting method (optical dissector) using the confocal microscope (Scott et al., 2000) was used to determine the number of positively labeled cells in six random sections of the dentate gyrus taken from each animal. The results from all sections were pooled and the mean from all sections is taken as $n=1$. 


\subsection{Microscopy}

Representative images were taken using a Nikon Optiphot-2 fluorescence microscope with either $20 \times$ dry lens or $100 \times$ oil immersion lens. The signal for Alexa 488 labeling (green) was detected using an Omega XF22 filter, and the Alexa 568 labeling (red) was detected using a Nikon BA590 filter. Images were digitized by a Sensicam CCD camera. Fluorescent signals for quantification were detected using a confocal microscope (Microsystems, Zeiss LSM 410) with $40 \times$ dry objective. A single wavelength laser line of $488 \mathrm{~nm}$ (ArKr laser) with LP515 filter was used to quantify the number of $\mathrm{Ki}-67 / \mathrm{BrdU}$ positive cells.

\section{Results}

In experiment 1 we compared the expression pattern of $\mathrm{Ki}-67$ and $\mathrm{BrdU}$ in tissue sections taken from brains of laboratory rats (Fig. 1). The two markers showed similar location of the labeled cells, primarily at the border of the hilus (core of the dentate gyrus), and the surrounding granule cell layer (GCL). This region is known as the proliferative zone. A few cells were also found in the hilus. Both markers are present in the nuclei of the labeled cells, as expected. This was shown using BrdU and Ki-67 co-labeling although this procedure was impractical for routine use (Fig. 2). To quantify the differences between $\mathrm{Ki}-67$ and $\mathrm{BrdU}$ labeling, six adjacent pairs of sections from each animal were labeled with either BrdU or Ki-67 and the numbers of labeled cells per section counted in each case. Estimates of the numbers of Ki-67-positive cells within the subgranular zone were as follows: in animals preinjected with BrdU $24 \mathrm{~h}$ prior to perfusion, we found 18.5 (S.E. $=1.7$, range $4-21$ cells/section, $n=4$ ) Ki-67- positive cells and 12.3 (S.E. $=1.1$, range $7-40$ cells/ section, $n=4)$ BrdU-positive cells $(t$-test, $P<0.05)$. Thus the Ki-67 method detected $50 \%$ more cells than the BrdU method. This is expected since $\mathrm{Ki}-67$ is expressed for the entire duration of the division cycle with the possible exception of early G1 (Section 4) (Scholzen and Gerdes, 2000) whereas BrdU can only be incorporated during the S-phase (DNA synthesis). Furthermore, we compared counts of Ki-67-labeled cells in control animals (19.8, S.E. $=2.4, n=3$ ), saline injected animals (23.9, S.E. $=0.95, n=3)$ and in the BrdU injected animals (18.5, S.E. $=3.4, n=4)$. The differences between the three groups were not statistically significant (one-way ANOVA, $P=0.15$ ). This experiment showed that $\mathrm{Ki}-67$ is a reliable method for measuring cell proliferation.

The presence of Ki-67-positive cells in the proliferative zone is consistent with previous observations of the newly-born cells in this region. However, cells expressing Ki-67 do not co-express the young neuronal marker CRMP-4 (Fig. 3). This may be explained by a delayed expression of CRMP-4 in cell development or by nonneuronal phenotype of the dividing cells. However, it has been shown previously that a large proportion of the new cells give rise to neurons and not glia (Cameron et al., 1993; Cameron and McKay, 2001). As expected, the mature neuronal marker NeuN was not co-labeled with Ki-67 (not illustrated).

Ki-67 can serve as a useful alternative to BrdU in experiments producing either an increase or decrease of proliferation. This is particularly important in treatments where BrdU labeling could, in principle, be altered by changes in the blood brain barrier permeability. It was recently shown that gamma irradiation reduces BrdU labeling (Tada et al., 2000; Snyder et al., 2001). In the present study we used a modified irradiation procedure where a ${ }^{60} \mathrm{Co}$ source was used allowing
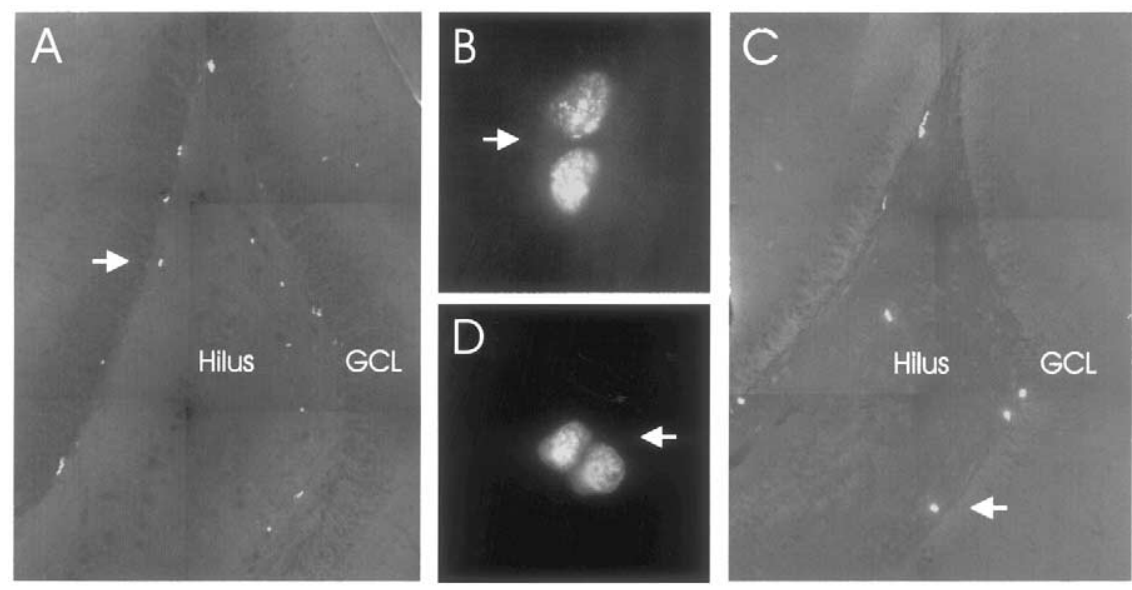

Fig. 1. Ki-67 and BrdU labeling in representative tissue sections from the rat dentate gyrus. (A) Alexa-568 labeling of Ki-67 positive nuclei. (B) High power view of selected Ki-67 positive nuclei (indicated by arrow). (C) Alexa-488 labeling of BrdU incorporated in nuclei (injected $24 \mathrm{~h}$ prior to the assay). (D) High power view of selected BrdU positive nuclei (indicated by arrow). GCL — granule cell layer. 

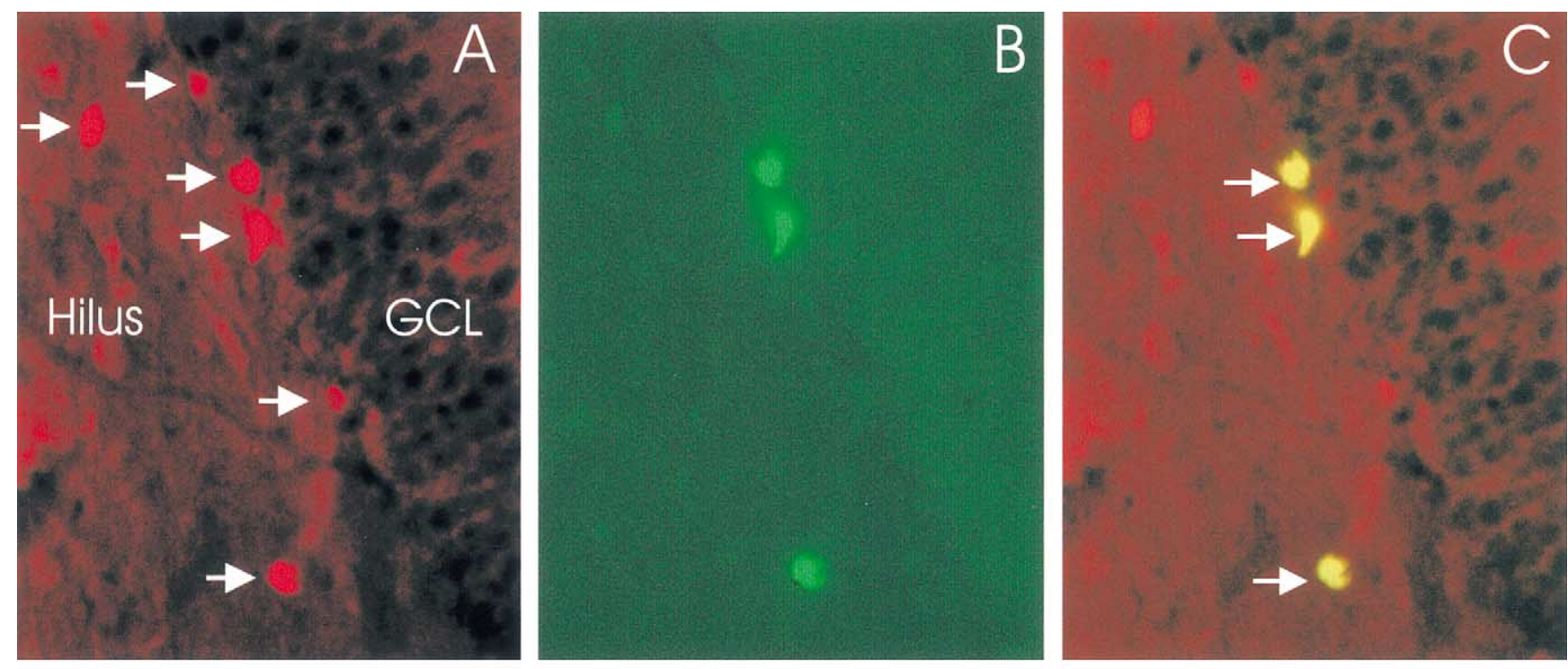

Fig. 2
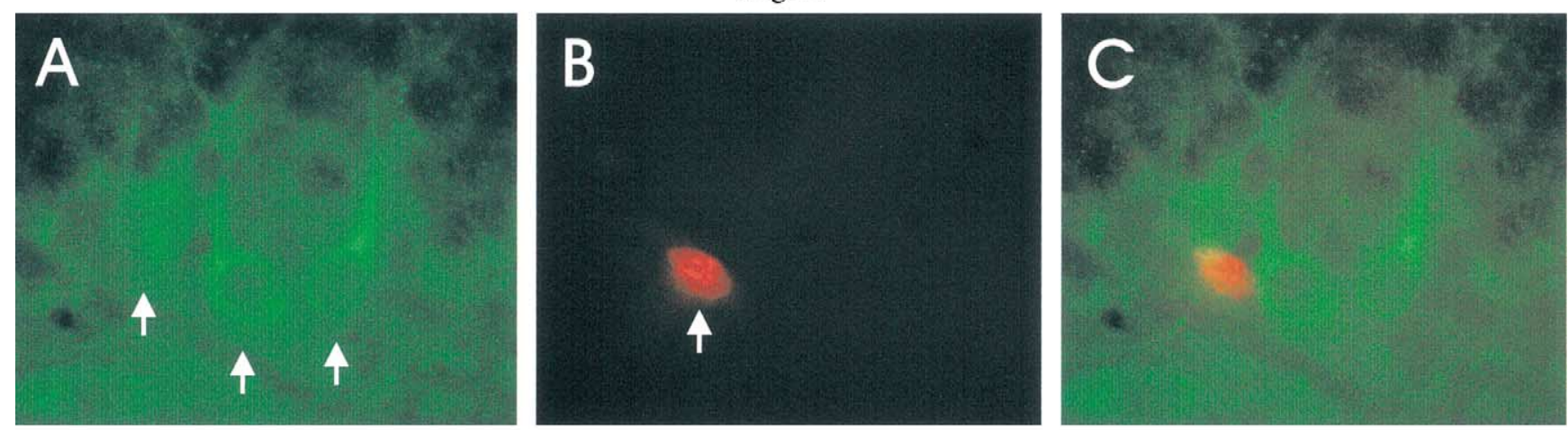

Fig. 3

Fig. 2. Ki-67 (red) and BrdU (green) co-labeling in a representative tissue section from the rat dentate gyrus. (A) Alexa-568 labeling of Ki-67 shows six identified nuclei (arrows). (B) Alexa-488 labeling of BrdU injected $24 \mathrm{~h}$ prior to the assay shows three nuclei. (C) Superimposed images A and B show that three out of six nuclei were labeled with both markers. GCL - granule cell layer.

Fig. 3. CRMP-4 (green) and Ki-67 (red) co-labeling in a tissue section from the rat dentate gyrus. (A) Alexa-488 labeling shows typical round cell bodies of CRMP-4 positive young neurons aligned along the proliferative zone. (B) Elongated Ki-67-positive nucleus in the same field. (C) Combined image illustrates that CRMP-4 and Ki-67 were present in different cells.

accurate focusing of the radiation beam on the head of the animal. In two irradiated animals, Ki-67 labeling was reduced by an average of $79 \%$ (Fig. 4), and that of BrdU by $60 \%$. The densities of the Ki-67 positive cells in the sham control group were 25.2 cells/section (S.E. $=$ $2.7, n=4)$. The densities of Ki-67 positive cells in the irradiated group were 5.1 cells/section (S.E. $=0.85, n=$ 2). The corresponding densities of the BrdU positive cells were 9.6 cells/section $($ S.E. $=1.65, n=4)$ before and 3.8 cells/section $(\mathrm{S} . \mathrm{E} .=0.02, n=2)$ after the irradiation. It should be noted that in this experiment, in contrast to experiment $1, \mathrm{BrdU}$ was injected $2 \mathrm{~h}$ and not $24 \mathrm{~h}$ prior to sacrificing the animals (Section 4).

Neurogenesis can be enhanced by a variety of stimuli including the transient ischemia produced by occlusion of the carotid arteries. The ischemia procedure leads to an approximately $100 \%$ increase in the density of the BrdU labeled cells (Kee et al., 2001). One possible explanation of this finding is that the increased labeling is caused by increased influx of BrdU into the brain due to a breakdown of the blood brain barrier after ischemia (Preston et al., 1993). To counter this argument we performed experiment 3 in which we used Ki-67 labeling in parallel with BrdU. We show that 10 days after ischemia similar proportional increases in the density of Ki-67 and of BrdU-positive cells were seen (Fig. 5). The densities of Ki-67 positive cells increased from 9.9 cells/ section (S.D. $=0.6, n=3$ ) in sham controls to 22 cells/ section (S.D. $=0.75, n=3$ ) in ischemic animals. The densities of the BrdU positive cells increased from 10.6 cells/section (S.D. $=0.75$ ) to 21.1 cells/section (S.D. $=$ $4.0, n=3)$. We conclude that the observed enhancement 
Control

Irradiated



Fig. 4. Ki-67 immunoreactivity in tissue sections from control and experimental rats after gamma irradiation. Note the decrease in proliferative activity after radiation treatment. GCL — granule cell layer.

of cell labeling seen after ischemia is not an artifact of BrdU method but due to increased cell proliferation.

\section{Control}


Perhaps the most beneficial feature of Ki-67 is that it can be readily used in species other than laboratory

\section{Ischemic}
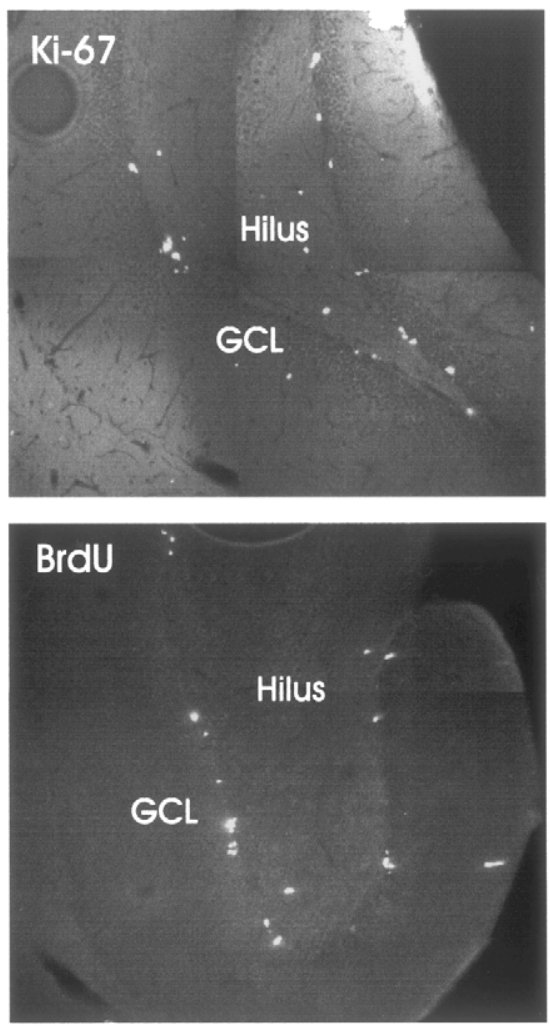

Fig. 5. Ki-67 and BrdU immunoreactivity in tissue sections from control and experimental rats 10 days after transient global ischemia. Note, both markers indicate an increase in proliferative activity after ischemia although the absolute levels are difficult to compare since BrdU was injected 3 days prior to the examination and Ki-67 shows a snap shot of the proliferation at the time of death. GCL-granule cell layer. 
rodents without the need for capturing, handling and injecting such as that required with BrdU. We have tested the use of $\mathrm{Ki}-67$ on brain tissue of the arctic ground squirrel (Spermophilus parryii), a rodent found in the tundra and alpine areas of mainland North America. Application of BrdU to these wild animals is not practical since their capture produces a strong stress response (Boonstra et al., 2001b) that in turn is known to suppress cell proliferation in the dentate gyrus in all species examined (Gould et al., 1998). Ki-67 may be a method of choice in such cases and it does indeed show proliferative activity in the dentate gyrus of the ground squirrel (Fig. 6).

\section{Discussion}

Neurogenesis in the adult dentate gyrus has been observed in all mammalian species examined to date, including humans (Eriksson et al., 1998). To establish a functional significance of the new neurons, one needs to determine that the proliferating cells respond to physiological stimuli, become integrated in the neuronal circuitry and are playing a significant role. Since the dentate gyrus of the hippocampus is one of the hot spots of neurogenesis, it is tempting to speculate that the new cells play a role in cognition and spatial learning, the established functions of this structure. Indeed the experiments on rats have shown that some types of hippocampal-dependent learning are critically influ- enced by the presence of the newly-born neurons (Gould et al., 1999; Shors et al., 2001). In other experiments the rate of cell proliferation was altered by physiological stimuli such as stress (Gould et al., 1997) or running (van Praag et al., 1999). However, until now BrdU has been used as a principal mitotic marker in such studies and it is prone to various difficulties. The main difficulty is that the administration of BrdU before or after the learning experiment is a potentially stressful procedure and stress can alter the BrdU incorporation into the dividing neurons (Gould et al., 1997, 1998). Numerous other side effects of BrdU, including a direct effect on adrenal gluocorticoid secretion, have been reported (Anisimov, 1994; Malendowicz et al., 1997) (Table 1). We addressed this problem in experiment 1 by examining the cell proliferation using Ki-67 in three groups of animals: one injected with BrdU $24 \mathrm{~h}$ prior to labeling, second injected with saline $24 \mathrm{~h}$ prior to labeling and third not injected at all. Contrary to the expectations there were no significant differences between the three groups suggesting that neither the injection procedure (presumed stress) nor BrdU itself had an inhibitory effect on the rate of cell division.

In experiment 2 we examined cell proliferation in the dentate gyrus before and after gamma irradiation applied through a ${ }^{60} \mathrm{Co}$ source to the head of the animal. In this experiment, unlike in experiment 1 , we injected BrdU $2 \mathrm{~h}$ prior to killing the animals. Assuming that there was no effect of stress due to the injection procedure, this experiment should give an accurate


Fig. 6. Ki-67/NeuN immunoreactivity in tissue sections from the Arctic ground squirrel. (A) NeuN labeled section of the dentate gyrus of a juvenile male arctic ground squirrel. (B) Ki-67 labeled section in the same animal shows characteristic immunoreactive nuclei of dividing cells in the subgranular proliferative zone (arrows). 
Table 1

Comparison of BrdU and $\mathrm{Ki}-67$ as proliferative markers

\begin{tabular}{|c|c|c|}
\hline & BrdU & $\mathrm{Ki}-67$ \\
\hline Selectivity & S-phase only (Gratzner, 1982) & $\begin{array}{l}\text { All phases of cell cycle except } \mathrm{G}_{0} \text { (Endl and Gerdes, 2000; } \\
\text { Scholzen and Gerdes, 2000) }\end{array}$ \\
\hline $\begin{array}{l}\text { Delivery and incorpora- } \\
\text { tion into tissue }\end{array}$ & $\begin{array}{l}\text { Dependent on dose, bioavailability and diffusion barriers } \\
\text { (Cameron and McKay, 2001) }\end{array}$ & Not dependant on dose, bioavailability or diffusion \\
\hline Expression across species & $\begin{array}{l}\text { Variable expression due to incorporation issues mentioned } \\
\text { above (Adelstein et al., 1964) }\end{array}$ & $\begin{array}{l}\text { Endogenous expression in all species examined thus far } \\
\text { (Endl and Gerdes, 2000; Scholzen and Gerdes, 2000) }\end{array}$ \\
\hline Use in cell fate tracking & $\begin{array}{l}\text { Feasible but with possible toxic effects during long } \\
\text { exposures (Anisimov, 1994; Kolb et al., 1999) }\end{array}$ & Not applicable \\
\hline Side effects & $\begin{array}{l}\text { Stress during injection and mutagenesis following incor- } \\
\text { poration (Anisimov, 1994; Malendowicz et al., 1997) }\end{array}$ & Not applicable (intrinsic expression) \\
\hline
\end{tabular}

Relevant references are given in parentheses.

comparison of $\mathrm{BrdU}$ and $\mathrm{Ki}-67$ labeling. In sham control animals we found that the ratio of BrdU/Ki-67 labeled cells was 0.38 consistent with the expected $\mathrm{BrdU}$ incorporation during the S-phase of the cell cycle only. In fact, approximate doubling of the BrdU labeled cells could be expected from 2 to $24 \mathrm{~h}$ survival as reported by Cameron and McKay (2001) due to mitotic divisions of the labeled cells. Although we did see a trend $(28 \%$ increase) towards the increased BrdU labeling in experiment 2 as compared to experiment 1 , the difference was not significant $(t$-test, $P=0.23)$. This observation doesn't conflict with the experiments of Cameron and McKay (2001) since a strict comparison between experiments 1 and 2 in our study is not possible due to significant differences in the procedures. For example, the ages of control animals were slightly different in the two experiments. Also, the sham procedures involved in the irradiation procedure were not trivial since they included transportation to and from the irradiation facility and anaesthesisa with pentobarbital. Our results with the irradiation suggest that the BrdU/Ki-67 ratio can change dramatically (from 0.38 before to 0.75 after irradiation) although more experiments will be needed to assess this change quantitatively and determine its cause.

The data from experiment 3 show considerably lower Ki-67 and BrdU counts in sham animals as compared to experiments 1 and 2. The lower rates of cell proliferation are expected due to the considerable age (Seki and Arai, 1995) and possibly strain differences (Wistar vs Sprague-Dawley) of rats used in these experiments (Section 2). Furthermore, in this experiment BrdU was injected 3 days prior the perfusions so the ratio of BrdU/ Ki-67 could have been changed by possible secondary divisions and cell death of the BrdU labeled cells in the three day period.

Another possible direction in such studies of neurogenesis will be to establish the effects of various stimuli on cell proliferation in other species, particularly those living in natural conditions and participating in natural behaviours such as finding and storing of food, finding mates etc. (Boonstra et al., 2001a). A non-invasive marker of neuronal proliferation such as $\mathrm{Ki}-67$ will be a valuable addition to the arsenal of experimental tools necessary for such studies. In Table 1 we compared the features of BrdU and $\mathrm{Ki}-67$. It shows that in experiments that involve tracing of the progeny and measuring the survival rates of the divided cells, BrdU is still the method of choice. Although this persistent presence of $\mathrm{BrdU}$ in the cells under study may produce long-term developmental abnormalities due to possible mutagenic activity (Anisimov, 1994; Kolb et al., 1999). The probable reason for such mutagenic effects is the substitution of CG by AT base pairs in the DNA and ineffectiveness of repair enzymes in case of BrdU induced DNA damage (Anisimov, 1994). No such effects have been reported in the case of adult neurogenesis so far (Cameron and McKay, 2001) but it should be realized that the assessment of cellular structure and function in these and other studies of adult neurogenesis has been quite limited and extended only over a period of several weeks. The blood-brain barrier and other metabolic factors (Adelstein et al., 1964; Cameron and McKay, 2001) may reduce the accessibility of BrdU in the brain in certain species while $\mathrm{Ki}-67$ is not prone to such difficulties. Thus, a comparative study of neuronal proliferation among different species or among different brain regions within a species should involve the use of Ki-67.

Our results from experiment 1 suggest that in laboratory rats, the presumed stress due to the injection of BrdU has no effect on the number of mitotically active cells in the dentate gyrus as shown by Ki-67 immunoreactivity. However, in other species, particularly in wild populations, the effect of captivity, handling, injections of BrdU and re-capture of animals could be significant (Boonstra et al., 2001b). In experiments that do not involve tracing of cells over long periods or those that must be done on wild animals or on human subjects where the invasiveness of BrdU may be a problem, Ki-67 is a welcome alternative. Although Ki67 is only a marker of cell proliferation it can be 
supplemented by other endogenous markers of young cells such as CRMP-4 (Kee et al., 2001).

The advantages of Ki-67 notwithstanding its application as a proliferative marker are not without some problems. For example it is not certain whether Ki-67 signal is strong enough to be detectable by immunohistochemistry during early G1, the initial phase of the cell cycle (Endl and Gerdes, 2000). Thus any changes in cell cycle during G1 may be undetectable.

Nevertheless Ki-67 is a useful marker of cell proliferation, the initial step in the fascinating process leading to production of new neurons in the adult brain. Thus future studies of neurogenesis should include both BrdU and $\mathrm{Ki}-67$ in combination with neuronal markers such as NeuN and CRMP-4, taking their advantages and limitations into account.

\section{Acknowledgements}

This research was supported by CIHR and the Heart and Stroke Foundation grants to JMW, and NSERC grant to RB. The assistance of Jason Snyder with the irradiation experiments is greatly appreciated.

\section{References}

Adelstein SJ, Lyman CP, O'Brien RC. Variations in the incorporation of thymidine into the DNA of some rodent species. Comp Biochem Physiol 1964;12:223-31.

Anisimov VN. The sole DNA damage induced by Bromodeoxyuridine is sufficient for initiation of both aging and carcinogenesis. Ann NY Acad Sci 1994;719:494-501.

Boonstra RA, Galea LAM, Matthews S, Wojtowicz JM. Hippocampal neurogenesis in natural populations. Can J Physiol Pharmacol 2001a;79:297-302.

Boonstra RA, Hubbs H, Lacey EA, McColl CJ. Seasonal changes in glucocorticoids and testosterone in free-living arctic ground squirrels from the boreal forest of the Yukon. Can J Zool 2001b;79:49-58.

Cameron H, Gould E. Adult neurogenesis is regulated by adrenal steroids in the dentate gyrus. Neuroscience 1994;61:203-9.

Cameron HA, McKay RDG. Adult neurogenesis produces a large pool of new granule cells in the dentate gyrus. J Comp Neurol 2001;435:406-17.

Cameron HA, Woolley CS, McEwen BS, Gould E. Differentiation of newly born neurons and glia in the dentate gyrus of the adult rat. Neuroscience 1993;56:337-44.

Endl E, Gerdes J. The Ki-67 Protein: fascinating forms and an unknown function. Exp Cell Res 2000;257:231-7.

Eriksson PS, Perfilieva E, Bjork-Eriksson T, Alborn AM, Nordborg C, Peterson DA, et al. Neurogenesis in the adult human hippocampus. Nat Med 1998;4:1313-7.
Gould E, Beylin A, Tanapat P, Reeves AJ, Shors TJ. Learning enhances adult neurogenesis in the hippocampal formation. Nat Neurosci 1999;2:260-5.

Gould E, McEwen BS, Tanapat P, Galea LAM, Fuchs E. Neurogenesis in the dentate gyrus of the adult tree shrew is regulated by psychosocial stress and NMDA receptor activation. J Neurosci 1997; 17:2492-8.

Gould E, Tanapat P, McEwen BS, Fluggge G, Fuchs E. Proliferation of granule cell precursors in the dentate gyrus of adult monkeys is diminished by stress. Proc Natl Acad Sci USA 1998;95:3168-71.

Gratzner HG. Monoclonal antibody to 5-Bromo- and 5-iododeoxyuridine: a new reagent for detection of DNA replication. Science 1982;218:474-5.

Gross CG. Neurogenesis in the adult brain: death of a dogma. Nat Rev 2000;1:67-73.

Kee N, Preston E, Wojtowicz JM. Enhanced neurogenesis after transient ischemia in the dentate gyrus of the rat. Exp Brain Res 2001;136:313-20.

Kolb B, Pedersen B, Ballermann M, Gibb R, Whishaw IQ. Embryonic and postnatal injections of bromodeoxyuridine produce agedependent morphological and behavioral abnormalities. J Neurosci 1999;19:2337-46.

Malendowicz LK, Nussdorfer GG, Trejer M. Effect of 5-Bromo-2deoxyuridine on the proliferative activity of thymus and regenerating adrenal cortex. Life Sci 1997;61:641-3.

Mullen RJ, Buck CR, Smith A. NeuN, a neuronal specific nuclear protein in vertebrates. Development 1992;116:201-11.

Palmer TD, Willhoite AR, Gage FG. Vascular niche for adult hippocampal neurogenesis. J Comp Neurol 2000;425:479-94.

Preston E, Sutherland G, Finsten A. Three openings of the bloodbrain barrier produced by forebrain ischemia in the rat. Neurosci Lett 1993;149:75-8.

Quinn CC, Gray GE, Hockfield S. A family of proteins implicated in axon guidance and outgrowth. J Neurobiol 1999;41:158-64.

Scholzen T, Gerdes J. The Ki-67 Protein: from the known and the unknown. J Cell Physiol 2000;182:311-22.

Scott BW, Wojtowicz JM, Burnham WM. Neurogenesis in the dentate gyrus of the rat following electroconvulsive shock seizures. Exp Neurol 2000;165:231-6.

Seki T, Arai Y. Highly polysialylated neural cell adhesion molecule (NCAM-H) is expressed by newly generated granule cells in the dentate gyrus of the adult rat. J Neurosci 1993;13:2351-8.

Seki T, Arai Y. Age-related production of new granule cells in the adult dentate gyrus. Neuroreport 1995;6:2479-82.

Shors TJ, Miesegaes G, Beylin A, Zhao M, Rydel T, Gould E. Neurogenesis in the adult is involved in the formation of trace memories. Nature 2001;410:372-6.

Snyder JS, Kee N, Wojtowicz JM. Effects of adult neurogenesis on synaptic plasticity in the rat dentate gyrus. J Neurophysiol 2001;85:2423-31.

Tada E, Parent JM, Lowenstein DH, Fike JR. X-irradiation causes a prolonged reduction in cell proliferation in the dentate gyrus of adult rats. Neuroscience 2000;99:33-41.

Tanapat P, Hastings NB, Reeves AJ, Gould E. Estrogen stimulates a transient increase in the number of new neurons in the dentate gyrus of the adult female rat. J Neurosci 1999;19:5792-801.

van Praag H, Kempermann G, Gage FH. Running increases cell proliferation and neurogenesis in the adult mouse dentate gyrus. Nat Neurosci 1999;2:266-70. 